\title{
Designing spline broaches of optimal structure
}

\author{
Svetlana Lukina ${ }^{1,2, *}$, Margarita Krutyakova $^{2}$, and Sergey Ivannikov ${ }^{2}$ \\ ${ }^{1}$ Moscow State University of Tehnology "STANKIN”, 3a Vadkovsky, Moscow 127055, Russian \\ Federation \\ ${ }^{2}$ Moscow polytechnic university, 38 B.Semyonovskaya st., Moscow 107023, Russian Federation
}

\begin{abstract}
Methods of designing spline broaches of optimal structure according to smallest length of body are described. Multitude of broach designs may be explained by summation of geometric, structural and operating parameters of working and tail parts. In order to evaluate the efficiency of spline broaches, a system of functions characterizing length of broach, round and chamfer parts in accordance with the cutting pattern is introduced. A system of structural and technological limitations over basic features of broaches is supported. Mathematical optimization model of a broach consisting of a sum of target functions and constraint system is put together. Choice of optimal solution is based on implementation of linear programming algorithms. Optimal methods of designing spline broaches are determined using MS Excel. The developed design method is applicable for comparative evaluation of spline broaches of various designs with various cutting and cut-off patterns and allows to form the entire sum of broach designs according to set input parameters and to choose the most efficient one which would correspond to minimal length of the tool.
\end{abstract}

\section{Introduction}

Broaching is one of the most productive methods of metal cutting. Broaching is used for roughing machining and finishing of both internal and external surfaces with high precision (7-6 degrees of precision) and low roughness $(\mathrm{Ra}=1.25 \ldots 2.5 \mu \mathrm{m})$. Broaching is 10 to 15 times more productive than that of drilling, core drilling, and hole reaming [1, 2]. Besides, when machining multispline holes, broaching is the only possible way of processing.

However, broach is a tool which is metal-consuming, complex and difficult to produce. The economic feasibility of their use is justified only when their design is optimal, rational cutting modes are chosen, and the tools themselves are properly manufactured and operated $[3,4]$.

The problem of choosing a rational design for spline broaches is a complex and multifaceted task that requires optimization of numerous geometric, constructive and operational parameters. One of the main issues in designing broaching is the selection of a suitable cutting pattern. The cutting pattern determines the sequence of cutting off the allowance from the workpiece and the sequence of formation of surface by the cutting elements of the tool. It allows showcasing of not only the change in the machined surface

\footnotetext{
*Corresponding author: lukina sv@mail.ru
} 
during machining, but also of the design of the tool's cutting part. In addition, the cutting pattern has a significant effect on the quality of the machined surface, the cutting force and the efficiency of the machining process as a whole. In most cases, spline broaching is done by a combined broach which processes both the internal diameter and the splines. Arrangement of the groups of teeth affects the productivity of broaches and the technology of their manufacture. According to [2], eight types of tooth arrangement for spline broaches have been designed and are currently used. At the same time, recommendations [2] do not clarify what type of broach should be chosen in specific manufacturing environment.

Existing methods are directed towards designing of broaches of equal durability and do not allow to choose the parameters of a tool according to optimal criteria [5-8].

The aim of this study is to develop a method of automatic design of spline broaches according to the working part's smallest length. To achieve the set objective, the following research tasks are stated in the paper: to form and analyze a total of criteria characterizing the efficiency of broaching; put together a set of performance functions of a spline broach's working part; develop a mathematical optimization model for choosing basic parameters of spline broaches according to the working part's smallest length; to implement the developed mathematical model in MS Excel.

\section{General provisions of methods of designing spline broaches with optimal structure}

There are multiple designs of spline broaches. The differences can be found in cutting patterns, arrangement of teeth, profile of teeth etc. In order to develop the method of computer-aided design, a model of a generalized broach design was developed in the form of an aggregate of sets, each of which defines some part of the tool design, a structural element or parameters of a part of the structure or a structural element [9]:

$$
l_{x}=\bigcup_{i=1}^{n_{l x 1 i}} x_{1}{ }^{i} \bigcup_{i=1}^{n_{l x 11}} x_{11}{ }^{i} \bigcup_{i=1}^{n_{l x 12}} x_{12}{ }^{i} \bigcup_{i=1}^{n_{l x 13}} x_{13}{ }^{i} \bigcup_{i=1}^{n_{l x 21}} x_{21}{ }^{i} \bigcup_{i=1}^{n_{l x 22}} x_{22}{ }^{i}
$$

Here $x_{11}, x_{12}, x_{13}$ - parameters of round, spline and chamfer parts respectively; $x_{1}$ parameters characterizing the working part of the broach as a whole; $x_{21}, x_{22}$ - parameters of the lead-in and tail sections respectively.

In each specific case, according to (1), a number of non-repetitive constructive, geometric and operational parameters can be established, according to which a tool is designed, including the parameters of the working part and the shank.

It has been established that, when solving the problem of choosing the optimal broach design, it is sufficient to determine the parameters of its working part, since the parameters of its tail part in the compared variants will be the same [1,2,10-13].

To assess the efficiency of specific spline broach designs, the criterion for ensuring the minimum length of the working part has been chosen. Reducing the length of the broach in comparison with the basic version of the design will reduce the cost of the tool by reducing the cost of materials and fabrication, as well as increase the productivity of broaching, other things being equal.

It is determined that the main structural parameters defining broaching in general are the parameters of its cutting part: tooth increment $S$, step $t$ and height $h$ (chip groove depth) of a tooth, number of teeth in a group (unit) $z_{c}$. The broach operation conditions are quite fully characterized by a cutting speed $v$ and a number of its admissible regrindings $n$. The parameters $S, t, h, v$ and $n$ are interconnected and cannot be determined in an unambiguous way. 
To ensure the procedure for selecting the optimal combination of broaching parameters, it is necessary to put together a series of analytical expressions that allow calculating the length of the tool. In this study, analytical dependencies between the criterion of optimality and the set of geometric, constructive and operational parameters of broaching are expressed in the form of objective functions. Moreover, each objective function contains only the elements of the criterion which can be represented functionally from the parameters of the broach being designed. Constants which are independent of the required parameters and which change only the absolute values of the objective functions without affecting the results of optimization were not taken into account during the calculations.

A system of objective functions characterizing the length of the splined, round and chamfer parts of the broach is developed in accordance with the allowance cutting pattern along the spline. For instance, length of the broach's spline part for patterns 'chamferspline-round' or 'chamfer-round-spline' is calculated according to the following formula:

$$
\begin{aligned}
& L_{s p}=t_{s p} \cdot\left(\frac{D_{a \max }-D_{e}-1-\frac{0,14}{Q G^{0,45}}}{2 S_{s p}} \cdot z_{c s p}+1\right)+ \\
& +\left(3 S_{o}+0,7\right) \cdot t_{s p}+\left(0,6^{Q G} \cdot 8,7 z_{c s p f}+10-0,6 K V\right) \cdot t_{s p f} \rightarrow \min
\end{aligned}
$$

Working length of the round and chamfer part is determined according to the following expressions:

$$
\begin{aligned}
& L_{c l}=t_{c l} \cdot\left[\frac{D_{f \max }-D_{0 \min }-1-\frac{0,14}{Q G} 0,45}{2 S_{c l}} \cdot z_{c c l}+10,5 \cdot S_{c l}+0,4\right]+ \\
& +\left((6,5-1,3 Q G) \cdot z_{c c l f}+10-0,6 K V-1\right) \cdot t_{c l f} \rightarrow \min \\
& L_{c h}=\left(\frac{D_{e}+0,2-D_{0 \min }-1}{2 S_{c h}} \cdot z_{c c h}+z_{c c h}\right) \cdot t_{c h} \rightarrow \min
\end{aligned}
$$

Here $D_{\text {amax }}, D_{\text {fmax }}$ - maximum diameter of chamfers' ledges and dents respectively; $D_{0}$ hole diameter before broaching; $D_{e}$ - nominal diameter of the last chamfer tooth; $t_{s p}, t_{c l}, t_{c h}$ - step of spline, round and chamfer tooth respectively; $S_{s p}, S_{c l}, S_{c h}$ - tooth increment in spline, round and chamfer parts of the broach respectively; $t_{s p f}, t_{c l f}$ - step of finishing teeth; $z_{c s p}, z_{c c l}, z_{c c h}$ - number of teeth per group in spline, round and chamfer parts of the broach; $G K$ - quality group of a machined surface; $K V$ - factor of the cutting speed.

The authors formed the following system of limitations for the changeable parameters of the broach working section:

$$
\left\{\begin{array}{c}
x_{1_{\min }} \leq x_{1} \leq x_{1_{\max }} \\
\cdots \ldots \ldots \ldots \ldots \ldots \ldots \ldots \ldots \\
x_{n_{\min }} \leq x_{n} \leq x_{n_{\max }}
\end{array}\right.
$$

Here, $x_{1 \min }, x_{\operatorname{lmax}}, \ldots, x_{n \min }, \ldots, x_{n \max }-$ minimum and maximum admissible values of structural, geometrical and operation broach parameters, correspondingly. 
Each minimal value of $x_{\min }$ is the maximum of the minimum allowed values of $x_{i}, x_{j}$, $x_{k}, \ldots, x_{n}$ parameters, and each maximum value of $x_{\max }$ is the minimum of the maximum allowed values of $x_{a}, x_{b}, x_{c}, \ldots, x_{m}$ parameters corresponding to a specific condition of the tool in accordance with design specifications [10]:

$$
\begin{array}{r}
x_{\min }=\max \left\{x_{i}, x_{j}, x_{k}, \ldots, x_{n}\right\} \\
x_{\max }=\min \left\{x_{a}, x_{b}, x_{c}, \ldots, x_{m}\right\}
\end{array}
$$

This system takes into account: admissible cutting strength depending on the machine pulling force, broach strength along the shank and the first tooth groove; filling degree of a chip groove, its reasonable dimensions taking into account the allowance for regrinding; tool stiffness, its ease of manufacturing; broach operation smoothness, stable workpiece positioning and efficiency of lubricating and cooling media application; admissible cutting speed and regrinding number, etc.

\section{Implementation of the methodology for automated design of broach optimum structures}

A developed mathematical model consisting of target functions (2) - (4) and the system of limitations (5) - (7) was implemented in the e-tables media Microsoft Excel. The authors formed a system of interconnected and interdependent electronic tables - modules such as insertion of input data - treated surface parameters; building and calculation of the system of limitations (5) - (7); building and calculation of target functions (2) - (4); analytical problem solution; graphical problem solution with the visualization of the feasibility region and choice of the optimum ones.

After input data insertion, the target functions and limitation system are automatically formed. The optimization problem is resolved by a simplex method. Transforming the model into a linear one is performed by means of logarithmation [14]. The general idea of the simplex method is the following. In case the initial linear programming problem has a solution, a corresponding set of admissible alternative options represents a certain polygon or, more strictly, a simplex in some space. If there is only one solution, the optimum value of a target linear function corresponding to a certain hyperplane is achieved in one of the vertices of this polygon (simplex). Therefore, the process of solution finding is limited by the direct search of the polygon (simplex) vertices only and check of corresponding values of a target function in terms of its optimality.

The formed system of e-tables allows for an automated building of the feasibility region depending on the input calculation data. In some cases, when a limitation system is too large or there are no doubts in terms of the feasibility region closedness, the mathematical model can be solved with the use of the integrated functions of solution finding. The formed electronic tables allow both for the calculation of an optimum solution and to form a feasible region - the polygon vertices. Such solutions may be further applied to analyze the broach structures.

A series of numerical experiments was carried out on the generated models by varying the numerical values of the set of parameters (1) in the given range boundaries (5) - (7). For various allowance cutting patterns, absolute values of the target functions ensuring the smallest length of spline broaches are obtained.

Calculations have shown that the criterion of the smallest length can successfully serve to evaluate various broach designs with a random number of teeth in the group since it takes into account the design features of single and group cutting and various allowance 
cutting patterns. The developed design method allows comparison the designs of spline broaches with different patterns of allowance cutting at the initial stages of designing and in an automated mode.

\section{Conclusion}

Calculation of spline broaches according to the smallest length provides designing of the most cost-effective and productive tool.

Designing of spline broaches with the smallest length is based on choosing the optimal combination of constructive, geometric and performance parameters and allowance cutting patterns from set limits.

The developed design method is applicable for comparative evaluation of spline broaches of various designs with various cutting and cut-off patterns and allows to form the entire sum of broach designs according to set input parameters and to choose the most efficient one which would correspond to minimal length of the tool.

\section{References}

1. C. Monday, Broaching, (The Machinery Publishing Co., London, 1960)

2. D.K. Margulis, M.M. Tverskoy, V.N. Ashihmin, Protjazhki dlja obrabotki otverstij, (Mashinostroenie, Moscow, 1986)

3. A.R. Maslov, Konstruirovanie instrumental'noi osnastki, (Moscow, Yanus-K Publ., 2012)

4. P. Gilormini, E. Felder, A Comparative Analysis of Three Machining Processes: Broaching, Tapping and Slotting, Annals of the CIRP, 33/1, pp. 19-22 (1984)

5. S. Hagglund, New Procedure for Optimizing Cutting Data for General Turning, Proc. Instn. Mech. Engrs., 217/B, pp.349-362 (2003)

6. R.H. Todd, D.K. Alltn, L. Alting, Manufacturing Processes Reference Guide, (Industrial Press Inc., Ney York, 1994)

7. A. Hosseini, H.A. Kishawy, On the Optimized Design of Broaching Tools, Journal of Manufacturing Science and Engineering, 136(1) (2013), doi:10.1115/1.4025415

8. O. Ozturk, M. Sc. Thesis, Modelling of Broaching Process, Industrial Engineering, (Sabanci University Publ, Istanbul, 2003)

9. S.V. Lukina, Metodika optimizacii proizvodstvennoj dejatel'nosti promyshlennogo predprijatija na osnove kompleksa prognosticheskih reshenij $v$ oblasti vysokotehnologichnyh proizvodstv, Vestnik MSTU «STANKIN», 1(32), pp. 125-129 (2015)

10. S. V. Lukina, Formation of the system of the local indicators to assess the quality of the cutting tool at the stage of technical training of production, Metal Working and Material Science, 4, pp.43-50 (2015), doi: 10.17212/1994-6309-2015-4-43-50

11. S.V. Lukina, Modeling of stresses-deformed state of inserted cutting tools during their production and operation, Avtomatizatsiya i Sovremennye Tekhnologii, 4, p.27 (2001)

12. A.A. Bekaev, Y.V. Maksimov, S.V. Lukina, Predicting the surface quality in discontinuous cutting. Russian Engineering Research, 35(10), p.792 (2015)

13. V.A. Grechishnikov, S.N. Grigor'ev, S.V. Lukina, Ju.M. Solomencev, A.G. Shirtladze, V.I. Vlasov, Processy $i$ operacii formoobrazovanija $i$ instrumental'naja tehnika, (Moscow, Janus-K Publ, 2006)

14. P. Mason, Computerized cutting-tool management, American machine and automatic manufacturing, 5, pp.106-113 (1986) 